\title{
Serum Magnesium Level of Newly Detected Patients with Glucose Intolerance and Its Comparison with Serum Magnesium Level of Age and Sex Matched Healthy Volunteers
}

\author{
MUHAMMAD ABDUR RAHIM, ${ }^{1}$ PALASH MITRA ${ }^{2}$
}

\begin{abstract}
Background: Hypomagnesaemia is associated with insulin resistance, diabetes mellitus (DM) and diabetic complications. Diabetic patients, on the other hand, often have low magnesium levels. This study was designed to evaluate serum magnesium level of patients with new diagnosis of any level of glucose intolerance e.g. impaired fasting glucose, impaired glucose tolerance (IGT) or DM and to compare these with serum magnesium level of age and sex matched healthy controls.

Materials \& Methods: This case-control study was done in out-patient department of BIRDEM General Hospital from July to September 20I7. Newly detected patients with glucose intolerance (DM 49, IGT I) were cases and equal number (50) of age and sex matched healthy volunteers were controls. Serum magnesium level was measures in all study participants and a comparison was made between cases and controls.

Results: There was no significant difference between cases and controls regarding age $(p=0.875)$, sex and body mass index $(P=0.386)$. Serum magnesium level was normal in 29 cases and 37 controls and low in 21 cases and 13 controls. Mean serum magnesium was low in cases $(0.70 \pm 0.14 \mathrm{~m} . \mathrm{mol} / \mathrm{L})$ than controls $(0.85 \pm 0.15 \mathrm{~m} . \mathrm{mol} / \mathrm{L})$ but the difference was not significant $(P=0.362)$. Serum magnesium level was negatively correlated with fasting blood glucose $(r-0.526), 2-h$ post-glucose value $(r-0.559)$ and glycated haemoglobin ( $r-0.55 I)$ among cases.

Conclusion: Serum magnesium level was lower among patients with DM and IGT when compared with serum magnesium level of age and sex matched healthy volunteers and serum magnesium level was negatively correlated with glycaemic status.
\end{abstract}

Key words: diabetes mellitus, glucose intolerance, impaired fasting glucose, impaired glucose tolerance, serum magnesium.

DOI: http://dx.doi.org//0.3329/jom.v19i2.37227

\section{Introduction}

Diabetes mellitus (DM) is a global public health problem. Globally 347 million people are having $\mathrm{DM}^{1}$ and this number is projected to be double in next 20 years and $150 \%$ more in low- and middle-income countries (LMIC). ${ }^{2-4}$ Over $90 \%$ of all diabetic patients are having type 2 diabetes mellitus (T2DM). ${ }^{5}$ Classically these patients pass through prediabetes [impaired fasting glucose (IFG) and impaired glucose tolerance (IGT)] states. Insulin resistance is one of the most important contributory aetio-pathogenic factors for T2DM development.

1. Assistant Professor, Nephrology, BIRDEM General Hospital and Ibrahim Medical College, Dhaka, Bangladesh.

2. Assistant Registrar, Nephrology, BIRDEM General Hospital, Dhaka, Bangladesh.

Corresponding author: Muhammad Abdur Rahim, Assistant Professor, Nephrology, BIRDEM General Hospital and Ibrahim Medical College, Dhaka, Bangladesh. Email: muradrahim23 (a)yahoo.com.

Received: 29 December 2017;

Accepted: 17 April, 2018
Low serum magnesium $(\mathrm{Mg})$ has been reported in patients with $\mathrm{DM}^{6-8}$ and specially south-Asians ${ }^{9}$ are at increased risk. Not only that, hypomagnesaemia is associated with insulin resistance ${ }^{9,10}$, thus contributing to causation of diabetes. ${ }^{11}$ Hypomagnesaemia is also associated with progression of diabetic complications. ${ }^{6,12}$ Uncontrolled diabetes leads to osmotic diuresis and hypomagnesaemia ${ }^{13}$ thus there occurs a vicious cycle ${ }^{14}$ of hypomagnesaemia, diabetes and hypomagnesaemia. Mg supplementation helps in achieving good glycaemic control and may prevent or delay complications. ${ }^{15,16}$ If patients with glucose intolerance are investigated and found to have low $\mathrm{Mg}$ levels, $\mathrm{Mg}$ replacement will help them to achieve better outcome. This study was designed to evaluate serum $\mathrm{Mg}$ level of newly detected patients with glucose intolerance, compare these values with serum $\mathrm{Mg}$ levels of age and sex matched healthy volunteers and to correlate level of serum $\mathrm{Mg}$ with glycaemic status of such patients.

\section{Materials \& Methods:}

This case-control study was done in out-patient department (OPD) of Bangladesh Institute of Research and Rehabilitation 
in Diabetes, Endocrine and Metabolic Disorders (BIRDEM) General Hospital, Dhaka, Bangladesh over a period of three months (July-September 2017). Fifty newly detected (disease duration $<3$ months) patients with glucose intolerance (DM 49, IGT 1) were taken as cases and 50 age and sex matched healthy volunteers were included in this study as controls. Patients with gestational diabetes mellitus (GDM), type 1 diabetes and other specific types of diabetes, patients on diuretic or laxative treatment, patients with diarrhea or vomiting, malabsorption syndrome, known cases of parathyroid disorders and diagnosed cases of electrolyte imbalance were excluded from the study.

The research protocol was approved by the Ethical Review Committee (ERC) of Bangladesh Diabetic Somiti (BADAS) before commencement of the study. Data were collected consecutively and purposively from patients who were detected as having any degree of glucose intolerance as per eligibility criteria [according to the most recent oral glucose tolerance test (OGTT), done within the last 3 months]. Patients were counseled regarding the purpose of the study in detail and if they agree, after having the informed written consent, they were tested for serum $\mathrm{Mg}$. Mg was tested by The ARCITECT c System family instruments manufactured by Abbott Laboratories, Abbott Park, IL, USA. Other relevant clinical and laboratory data were taken from patients' records which were done as part of routine management. Equal number of age and sex matched healthy volunteers were taken as control.

Data were analyzed by using statistical package for social sciences (SPSS) version 20.0 and appropriate statistical tests were performed. Results were presented in tables and figures as appropriate.

\section{Results:}

Total 50 patients with glucose intolerance (cases) and 50 age and sex matched healthy volunteers (controls) were evaluated in this study. Base-line characteristics are shown in Table I. Serum Mg level was normal in 29 cases and 37 controls and low in 21 cases and 13 controls. Mean serum $\mathrm{Mg}$ was lower in cases than controls but the difference was not significant ( $\mathrm{p}=0.362$ ). Serum $\mathrm{Mg}$ level was negatively correlated with fasting blood glucose (FBG), 2-h post-glucose value and glycated haemoglobin (HbA1c) among cases ( $\mathrm{r}$ $0.526,-0.559$ and -0.551 respectively) (Figure 1, 2, 3 respectively) but there was no significant relation of serum Mg with random blood glucose in control group (r 0.182).

Table I

Base-line characteristics of cases (50) and controls (50).

\begin{tabular}{|c|c|c|c|}
\hline Characteristics & Cases (N-50) & Controls (N-50) & $\mathrm{p}$ value \\
\hline Age (years) & $43.68 \pm 11.07$ & $43.26 \pm 11.23$ & 0.875 \\
\hline Male:Female & $1: 1.5$ & $1: 1.5$ & $\longrightarrow$ \\
\hline $\operatorname{BMI}\left(\mathrm{kg} / \mathrm{m}^{2}\right)$ & $27.70 \pm 1.98$ & $25.33 \pm 2.64$ & 0.386 \\
\hline Systolic BP (mm Hg) & $133.10 \pm 14.87$ & $122.50 \pm 10.06$ & $0.001 *$ \\
\hline Diastolic BP (mm Hg) & $83.00 \pm 6.22$ & $76.94 \pm 9.71$ & $0.004 *$ \\
\hline DM:IGT & $49: 1$ & - & - \\
\hline FBG (m.mol/L) & $8.98 \pm 1.90$ & $\longrightarrow$ & - \\
\hline 2-h BG (m.mol/L) & $14.52 \pm 7.22$ & - & - \\
\hline RBG(m.mol/L) & - & $6.50 \pm 0.38$ & - \\
\hline HbA1c $(\%)$ & $7.87 \pm .93$ & - & $\longrightarrow$ \\
\hline $\operatorname{Mg}(\mathrm{m} . \mathrm{mol} / \mathrm{L})$ & $0.70 \pm 0.14$ & $0.85 \pm 0.15$ & 0.362 \\
\hline $\mathrm{Ca}(\mathrm{mg} / \mathrm{dL})$ & $8.78 \pm 0.28$ & $8.52 \pm 1.27$ & $0.004 *$ \\
\hline S. Creatinine $(\mathrm{mg} / \mathrm{dL})$ & $0.89 \pm .145$ & $0.81 \pm .096$ & $0.002 *$ \\
\hline $\operatorname{ALT}(\mathrm{U} / \mathrm{L})$ & $52.46 \pm 10.02$ & $41.62 \pm 15.48$ & $0.001 *$ \\
\hline
\end{tabular}

[BMI-body mass index, BP-blood pressure, DM-diabetes mellitus, IGT-impaired glucose tolerance, FBG-fasting blood glucose, RBG-random blood glucose, HbAlc-glycated haemoglobin, ALT-alanine aminotransferase ] 


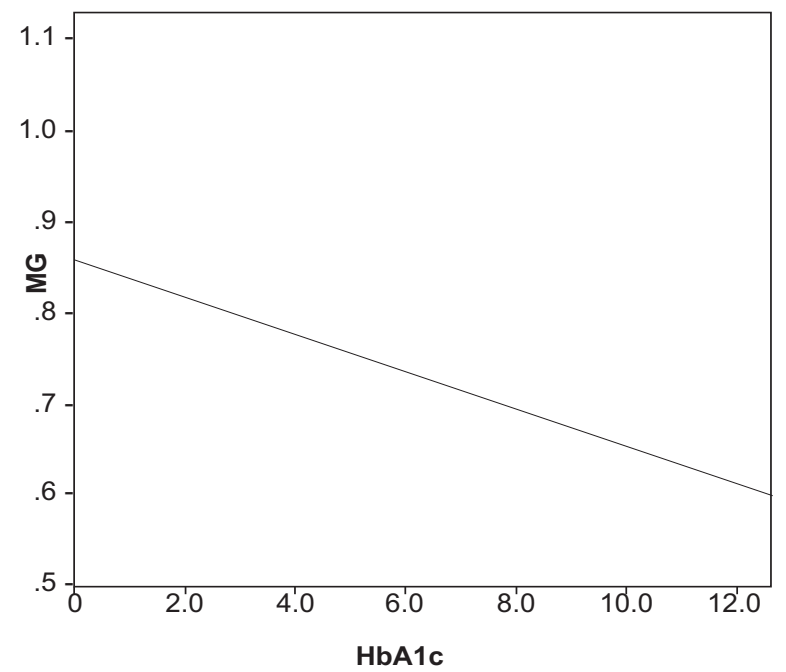

Figure 1. Relationship between $\mathrm{HbA1c}$ and serum $\mathrm{Mg}$ level among cases.

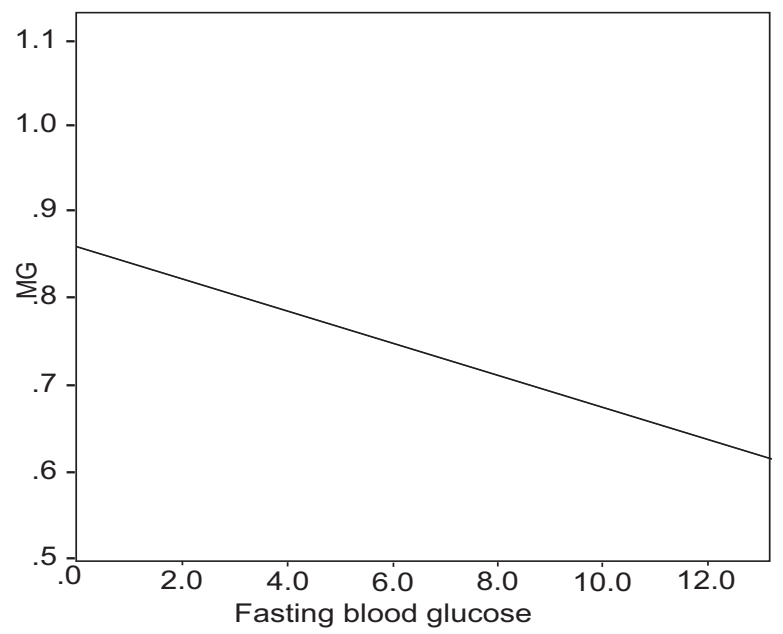

Figure 2. Relationship between FBG and serum $\mathrm{Mg}$ level among cases.

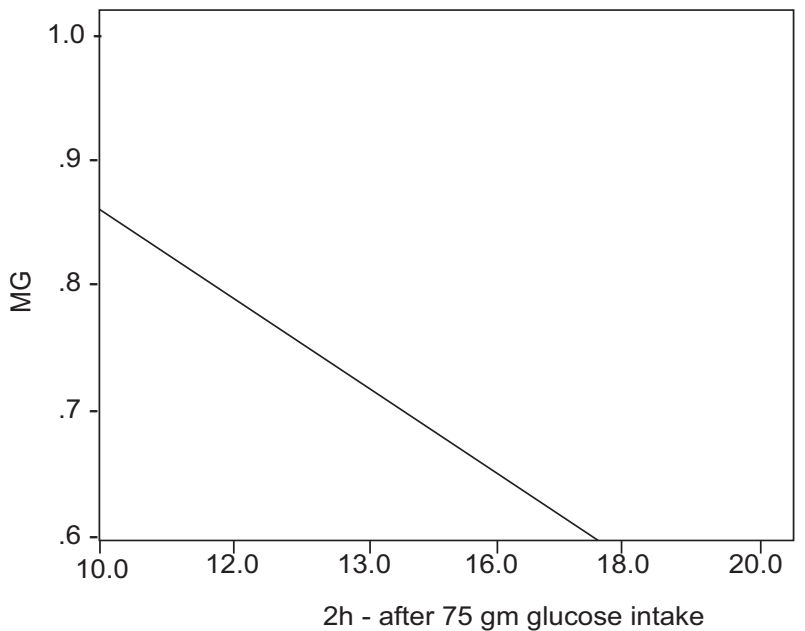

Figure 3. Relationship between 2-h after 75 gm glucose and serum $\mathrm{Mg}$ among cases.

\section{Discussion:}

$\mathrm{Mg}$ is the second most major intracellular cation in the human body. It is the basic composition of many enzymes and acts as a cofactor in over 300 enzymatic reactions. ${ }^{17}$ Evidences suggest that low $\mathrm{Mg}$ is related to insulin resistance thus contributing to the development of DM. ${ }^{9,10,18}$ Dietary $\mathrm{Mg}$ supplementation may prevent conversion from prediabetes to diabetes. ${ }^{16}$ Hypomagnesaemia in diabetic population is associated with neuropathy and other diabetic complications. ${ }^{19,20}$ Among diabetic patients, there is a higher renal $\mathrm{Mg}$ excretion caused by reduced tubular $\mathrm{Mg}$ reabsorption resulting from glucose-induced osmotic diuresis and possibly resulting from insulin resistance. ${ }^{13,14}$

Results from current study showed that $\mathrm{Mg}$ level was low in newly detected patients with glucose intolerance and there was inverse relation of $\mathrm{Mg}$ with their glycaemic control. Almost similar findings were observed in one Canadian study. ${ }^{21}$ Serum $\mathrm{Mg}$ level was negatively correlated with $\mathrm{HbAl} \mathrm{c}$ in different studies ${ }^{22-24}$ and it is a consistent finding.

As correction of hypomagnesaemia have positive impact on glycaemic control, dietary supplementation may help patients with diabetes, though controversies do exist. ${ }^{17}$ Newer antidiabetic agent, sodium-glucose co-transporter 2 (SGLT2) inhibitors have been reported to increase serum $\mathrm{Mg}$ level in diabetic patients. ${ }^{25}$

Most studies related to serum $\mathrm{Mg}$ and diabetes were done among diagnosed diabetic patients. Half of type 2 diabetic patients remain undetected and one-third to half of type 2 diabetic patients have one or more complications during diabetes diagnosis. ${ }^{26-28}$ As evidences suggest that correction of hypomagnesaemia improves diabetes control and delay complications, identification and treatment of hypomagnesaemia early in disease course will obviously improve overall patient outcome. Evaluation of $\mathrm{Mg}$ level early among patients with glucose intolerance and the casecontrol design of the present study were the main strengths of our study.

However, the present study had some limitations. It was a single center study with small number of study participants. No patient with IFG was included in this study. A larger multi-center study with increased number of study participants would give a more representative answer in question.

\section{Conclusion:}

Though there was no significant difference in serum $\mathrm{Mg}$ level among newly detected patients with glucose intolerance with serum $\mathrm{Mg}$ level of age and sex matched healthy volunteers in this study, serum Mg level was lower among 
patients with glucose intolerance (DM and IGT). Among patients with glucose intolerance serum $\mathrm{Mg}$ level was negatively correlated with glycaemic status.

Funding: This research work was funded by Bangladesh Society of Medicine (BSM).

\section{Conflict of interest: None.}

\section{References:}

1. Danaei G, Finucane MM, Lu Y, Singh GM, Cowan MJ, Paciorek CJ, et al. National, regional and global trends in fasting plasma glucose and diabetes prevalence since 1980: systematic analysis of health examination surveys and epidemiological studies with 370 country-years and 2.7 million participants. Lancet 2011;378(9785):31-40.

2. Fagot-Campagna A, Bourdel-Marchasson I, Simon D. Burden of diabetes in an aging population: prevalence, incidence, mortality, characteristics and quality of care. Diabetes Metab 2005;25:S35-S52.

3. Zimmet P. The burden of type 2 diabetes: are we doing enough? Diabetes Metab 2003; 29:6S9.

4. FffVanDieren S, Beulens JW, van der Schouw YT, Grobbee DE, Neal B. The global burden of diabetes and its complications: an emerging pandemic. Eur J Cardiovasc Prev Rehabil 2010;17:S3-S8.

5. Definition, diagnosis and classification of diabetes mellitus and its complications. Part 1: Diagnosis and classification of diabetes mellitus. Geneva, World Health Organization, 2011.

6. Xu J, Xu W, Yao H, Sun W, Zhou Q, Cai L. Association of Serum and Urinary Magnesium with the Pre-Diabetes, Diabetes and Diabetic Complications in the Chinese Northeast Population. PLoS ONE 2013;8(2):e56750.

7. Khan LA, Alam ASM, Ali L, Gowshami A, Hassan Z, Sattar $S$, et al. Serum and urinary magnesium in young diabetic subjects in Bangladesh. Am J Clin Nutr 1999;69:70-73.

8. Hyassat D, Sitri EA, Batieha A, El-Khateeb M, Ajlouni K. Prevalence of Hypomagnesaemia among Obese Type 2 Diabetic Patients Attending the National Center for Diabetes, Endocrinology and Genetics (NCDEG). Int J Endocrinol Metab 2014;12(3):e17796.

9. Bertinato J, Xiao CW, Ratnayake WMN, Fernandez L, Lavergne C, Wood C, et al. Lower serum magnesium concentration is associated with diabetes, insulin resistance, and obesity in South Asian and white Canadian women but not men. Food Nutr Res 2015;59:10.3402/fnr.v59.25974.

10. Chutia H, Lyrnah KG. Association of Serum Magnesium Deficiency with Insulin Resistance in Type 2 Diabetes Mellitus. J Lab Physicians 2015;7(2):75-78.
11. Yang SJ, Hwang SY, Baik SH, Lee KW, Nam MS, Park YS, et al. Serum Magnesium Level Is Associated with Type 2 Diabetes in Women with a History of Gestational Diabetes Mellitus: The Korea National Diabetes Program Study. J Korean Med Sci 2014;29:84-89.

12. Madihi Y, Marikhi A, Nasri H. Prevention of Hypomagnesemia in Diabetes Patients. Int J Prev Med 2013;4(8):982-983.

13. Pham PC, Pham PM, Pham SV, Miller JM, Pham PT. Hypomagnesemia in patients with type 2 diabetes. Clin J Am Soc Nephrol 2007;2:366-373.

14. Gommers LM, Hoenderop JG, Bindels RJ, de Baaij JH. Hypomagnesemia in Type 2 Diabetes: A Vicious Circle? Diabetes 2016;65(1):3-13.

15. Barbagallo M, Dominguez LJ. Magnesium and type 2 diabetes. World J Diabetes 2015;6(10):1152-1157.

16. Hruby A, Meigs JB, O’Donnell CJ, Jacques PF, McKeown NM. Higher Magnesium Intake Reduces Risk of Impaired Glucose and Insulin Metabolism and Progression From Prediabetes to Diabetes in Middle-Aged Americans. Diabetes Care 2014;37:419-427.

17. Wei J, Zeng C, Li X, Gong Q, Lei G, Yang T. Association among dietary magnesium, serum magnesium, and diabetes: a crosssectional study in middle-aged and older adults. Journal of Health, Population and Nutrition 2016;35:33.

18. Barbagallo M, Dominguez LJ, Galioto A, Ferlisi A, Cani C, Malfa L, et al. Role of magnesium in insulin action, diabetes and cardio-metabolic syndrome X. Mol Aspects Med 2003;24(1-3):39-52.

19. Chu C, Zhao W, Zhang Y, Li L, Lu J, Jiang L. Low serum magnesium levels are associated with impaired peripheral nerve function in type 2 diabetic patients. Sci Rep 2016;6:32623.

20. Larsson SC, Wolk A. Magnesium intake and risk of type 2 diabetes: A meta-analysis. J Intern Med 2007;262:208-214.

21. Bertinato J, Wang KC, Hayward S. Serum Magnesium Concentrations in the Canadian Population and Associations with Diabetes, Glycemic Regulation, and Insulin Resistance. Nutrients 2017;9:296.

22. Pokharel DR, Khadka D, Sigdel M, Yadav NK, Kafle R, Sapkota RM, et al. Association of serum magnesium level with poor glycemic control and renal functions in Nepalese patients with type 2 diabetes mellitus. Diabetes Metab Syndr 2017;pii:S1871-4021(17)30014-0.

23. Doddigarla Z, Parwez I, Ahmad J. Correlation of serum chromium, zinc, magnesium and SOD levels with $\mathrm{HbA} 1 \mathrm{c}$ in 
type 2 diabetes: A cross sectional analysis. Diabetes Metab Syndr 2016;10(1 Suppl 1):S126-9.

24. Odusan OO, Familoni OB, Odewabi AO, Idowu AO, Adekolade AS. Patterns and Correlates of Serum Magnesium Levels in Subsets of Type 2 Diabetes Mellitus Patients in Nigeria. Indian J Endocrinol Metab 2017;21(3):439-442.

25. Tang H, Zhang X, Zhang J, Li Y, Del Gobbo LC, Zhai S, et al. Elevated serum magnesium associated with SGLT2 inhibitor use in type 2 diabetes patients: a meta-analysis of randomised controlled trials. Diabetologia 2016;59(12):2546-2551.
26. Kohner EM, Aldingion SJ, Stratton IM, Manlet SE, Holman RR, Matthews DR, et al. United Kingdom Prospective Diabetes Study, 30: diabetic retinopathy at diagnosis of noninsulin-dependent diabetes mellitus and associated risk factors. Arch Ophthalmol 1998;116:297-303.

27. Heydari I, Radi V, Razmjou S, Amiri A. Chronic complications of diabetes mellitus in newly diagnosed patients. International Journal of Diabetes Mellitus 2010;2:61-63.

28. Deepa DV, Kiran BR, Srikant GR. Macrovascular and Microvascular Complications in Newly Diagnosed Type 2 Diabetes Mellitus. Indian Journal of Clinical Practice 2014;25(7):644-648. 